\title{
Cardiovascular mortality after pre-eclampsia in one child mothers: prospective, population based cohort study

\author{
Rolv Skjaerven professor ${ }^{12}$, Allen J Wilcox senior investigator ${ }^{3}$, Kari Klungsøyr associate professor ${ }^{12}$, \\ Lorentz M Irgens professor ${ }^{12}$, Bjørn Egil Vikse associate professor ${ }^{45}$, Lars J Vatten professor ${ }^{6}$, \\ Rolv Terje Lie professor $^{12}$
}

${ }^{1}$ Department of Public Health and Primary Health Care, University of Bergen, Bergen, Norway; ${ }^{2}$ Medical Birth Registry of Norway, National Institute of Public Health, Bergen; ${ }^{3}$ National Institute of Environmental Health Sciences, National Institute of Health, Research Triangle Park, North Carolina, USA; ${ }^{4}$ Institute of Medicine, University of Bergen; ${ }^{5}$ Department of Medicine, Haukeland University Hospital, Bergen; ${ }^{6}$ Department of Public Health, Norwegian University of Science and Technology, Trondheim, Norway

\begin{abstract}
Objective To assess the association of pre-eclampsia with later cardiovascular death in mothers according to their lifetime number of pregnancies, and particularly after only one child.

Design Prospective, population based cohort study.

Setting Medical Birth Registry of Norway.

Participants We followed 836147 Norwegian women with a first singleton birth between 1967 and 2002 for cardiovascular mortality through linkage to the national Cause of Death Registry. About 23000 women died by 2009, of whom 3891 died from cardiovascular causes. Associations between pre-eclampsia and cardiovascular death were assessed by hazard ratios, estimated by Cox regression analyses. Hazard ratios were adjusted for maternal education (three categories), maternal age at first birth, and year of first birth
\end{abstract}

Results The rate of cardiovascular mortality among women with preterm pre-eclampsia was $9.2 \%$ after having only one child, falling to $1.1 \%$ for those with two or more children. With term pre-eclampsia, the rates were $2.8 \%$ and $1.1 \%$, respectively. Women with pre-eclampsia in their first pregnancy had higher rates of cardiovascular death than those who did not have the condition at first birth (adjusted hazard ratio 1.6 (95\% confidence interval 1.4 to 2.0 ) after term pre-eclampsia; 3.7 (2.7 to 4.8 ) after preterm pre-eclampsia). Among women with only one lifetime pregnancy, the increase in risk of cardiovascular death was higher than for those with two or more children (3.4 (2.6 to 4.6) after term pre-eclampsia; 9.4 (6.5 to 13.7) after preterm pre-eclampsia). The risk of cardiovascular death was only moderately elevated among women with pre-eclamptic first pregnancies who went on to have additional children (1.5 (1.2 to 2.0) after term pre-eclampsia; 2.4 (1.5 to 3.9) after preterm pre-eclampsia). There was little evidence of additional risk after recurrent pre-eclampsia. All cause mortality for women with two or more lifetime births, who had pre-eclampsia in first pregnancy, was not elevated, even with preterm pre-eclampsia in first pregnancy (1.1 (0.87 to 1.14$)$ )

Conclusions Cardiovascular death in women with pre-eclampsia in their first pregnancy is concentrated mainly in women with no additional births. This association might be due to health problems that discourage or prevent further pregnancies rather than to pre-eclampsia itself. As a screening criterion for cardiovascular disease risk, pre-eclampsia is a strong predictor primarily among women with only one child-particularly with preterm pre-eclampsia.

\section{Introduction}

It is well established that women who have a pre-eclamptic pregnancy are at increased risk of death from cardiovascular diseases. $^{1-5}$ This risk is higher among women with preterm pre-eclampsia, a more severe expression of the condition. ${ }^{35}$ Analysis of mortality risk has typically been restricted to pre-eclampsia in first pregnancies - a rational strategy, since the risk of pre-eclampsia is highest in first births. However, a possible shortcoming of this approach has been raised by recent papers on mortality and parity. ${ }^{67}$ The authors found a $50 \%$ increase in mortality from circulatory diseases among women with only one child. Although it has previously been recognised that childless women have an increased risk of death from cardiovascular disease, raised mortality among women with just one child was unexpected.

The authors did not consider mortality after specific pregnancy outcomes. In view of the strong association between pre-eclampsia and subsequent maternal mortality (specifically cardiovascular death), we explored the possibility that women with pre-eclampsia in their first pregnancy and no additional 
pregnancies might be at particularly high risk. We pursued this question in a prospective, population based cohort study, by linking data from population based registries of birth and mortality in Norway, covering 42 years of observation.

\section{Methods}

Based on compulsory notification, the Medical Birth Registry of Norway has since 1967 recorded medical data on all births in the country with a gestational age of at least 16 weeks, ${ }^{8}$ including information on maternal disease and conditions of the newborn. Data are registered by the attending midwife and doctor using a standardised notification form, either as free text or by predefined variables or check boxes. Free text is coded at the Medical Birth Registry using the ICD (international classification of diseases, 8th revision for years 1967-98; 10th revision since 1999).

The criteria for pre-eclampsia in the Medical Birth Registry of Norway are in accordance with the 1972 recommendations of the American College of Obstetricians and Gynecologists': increased blood pressure after 20 weeks' gestation (defined as blood pressure 140/90 $\mathrm{mm} \mathrm{Hg}$ or greater; or an increase in systolic blood pressure of $\geq 30 \mathrm{~mm} \mathrm{Hg}$ or increase in diastolic blood pressure of $\geq 15 \mathrm{~mm} \mathrm{Hg}$, from measurements before 20 weeks of gestation), and proteinuria ( $\geq 0.3 \mathrm{~g}$ in $24 \mathrm{~h}$ urine specimen, or $\geq 1$ point increase on urinary dipstick). A validation study of pre-eclampsia in the Medical Birth Registry showed that registered pre-eclampsia corresponds well with medical records. ${ }^{10}$ A recent study on trends for pre-eclampsia in Norway ${ }^{11}$ also concluded an increase in the condition over the period 1967-98, owing to an improved case ascertainment over time. Using the national identification number, we linked each mother to her births for the period 1967-2009, yielding about 1.2 million mothers and 2.5 million births. For the present study, we restricted the analyses to 836147 women who had their first singleton birth (from 22 weeks' gestation) between 1967 and 2002, which allowed us to include second births that occurred within seven years after the first birth. About $95 \%$ of Norwegian women with two or more births had their second birth within seven years. Data for these women were linked to the national Cause of Death Registry through December 2009. Loss to follow-up owing to emigration from Norway was low $(<1 \%)$.

We classified causes of maternal death according to ICD-10 for the years 1996-2009, ICD-9 for 1986-95, and ICD-8 for 1969-85). In addition to total mortality, we analysed deaths due to:

- Diseases of the circulatory system: I00-I99 (ICD-10), 390-459 (ICD-8 and ICD-9)

- Ischaemic heart diseases: I20-I25 (ICD-10), 410-414, (ICD-8 and ICD-9)

- Cerebrovascular diseases (stroke): I60-I69 (ICD-10), 430-438 (ICD-8 and ICD-9)

We combined deaths from coronary heart disease and stroke into one entity denoted "cardiovascular deaths" for most of our analyses. Among the 836147 women who were included, 23 009 died during follow-up, and 3891 of the deaths were due to diseases of the circulatory system.

We aimed to assess how additional births after a pre-eclamptic pregnancy could influence later risk of death from cardiovascular causes, as well as all cause mortality, while taking account of the number of births. We constructed a composite variable that combined the number of births (one $v$ two or more) with the outcome of the first pregnancy (term and no pre-eclampsia, term pre-eclampsia, and preterm pre-eclampsia). This composite provided an "exposure" variable with six categories (tables $1 \Downarrow$ and $2 \Downarrow$ ). Thus, we studied the association of pre-eclampsia, indicated by term or preterm delivery, with the risk of deaths, and assessed whether the associations differed by the number of births in a woman's lifetime.

In a subanalysis of fathers, we used the same analytical strategy and selection criteria as for mothers. The identification number of fathers was missing in 17369 (2.1\%) of the first births, and we excluded sibships if the mother had a new partner in her second pregnancy. Thus, our analysis included 659732 fathers and 37441 deaths (12 066 deaths due to cardiovascular causes).

We constructed graphs from standard life tables and summarised mortality using Cox proportional hazard models (SPSS for Windows version 19.0, and Stata version 11.0). We tested for effects of interaction between the number of pregnancies (one $v$ two or more) and pre-eclampsia in the first pregnancy using Wald $\chi^{2}$ tests, as available in SPSS and Stata. The time variable in the Cox models was "time from first birth to death." We adjusted for (maternal or paternal) age at first birth (using a linear term), year of first birth (using a linear term), education (stratified into: did not complete high school (low level), completed high school (14 years' education; medium), educated beyond high school (high)). We also evaluated the results using categorical variables for year of birth (in five year periods) and age at first birth (in five year categories: <20, 20-24, 25-29, $30-34, \geq 35$ years). Where these were analysed, we found slightly stronger results. Missing values for these variables were rare: both maternal age and year of birth were complete, and maternal education was $98.5 \%$ complete. Preterm birth is defined as a delivery occurring between 22 and 36 completed weeks of gestation. Data for gestational age were missing for $3.7 \%$ for the years 1967-80, while 5\% were missing for the later years. Estimating gestational age by birth weight ( $99.8 \%$ complete), and predicting $<2500 \mathrm{~g}$ as preterm, slightly increased the hazard ratios in table 1 .

\section{Results \\ Parity and total mortality}

The majority of mothers, $700400(84 \%)$ had two or more children during their lifetime. Consistent with the earlier study, ${ }^{6}$ women with only one child had higher total mortality than women with two or more births (adjusted hazard ratio 1.9, 95\% confidence interval 1.9 to 2.0 ).

\section{Pre-eclampsia, parity, and total mortality}

In our analysis, 34824 (4.2\%) women had pre-eclampsia in their first pregnancy. Considering all women, pre-eclampsia in the first pregnancy was associated with a slight increase in total mortality (adjusted hazard ratio 1.1, 95\% confidence interval 1.0 to 1.1 ; table 1 ). This risk was concentrated entirely among women with preterm pre-eclampsia (1.4, 1.2 to 1.6). Among women with only one child, the risk added by pre-eclampsia was again entirely among the women with preterm pre-eclampsia (3.1 (2.5 to 3.9); table 1). One child mothers with term birth had the same increase in mortality risk regardless of whether they had pre-eclampsia or not (adjusted hazard ratios 1.8 and 1.9 , respectively). Among women with two or more lifetime pregnancies, there was no apparent increase in total mortality after either term pre-eclampsia $(1.0,0.90$ to 1.1$)$ or preterm pre-eclampsia $(1.1,0.87$ to 1.4$)$ in the first pregnancy. 


\section{Pre-eclampsia, parity, and cardiovascular mortality}

Since pre-eclampsia has been associated specifically with cardiovascular disease risk, we divided mortality into cardiovascular and non-cardiovascular causes. Women with pre-eclampsia in the first pregnancy had nearly a doubling of cardiovascular mortality risk overall, compared with those who did not have pre-eclampsia (adjusted hazard ratio 1.9, 95\% confidence interval 1.6 to 2.2 ; table 1 ), but no increase in other causes of death $(0.93,0.86$ to 1.00$)$. Cardiovascular risk was higher after preterm pre-eclampsia than after term pre-eclampsia (hazard ratio $3.7 v 1.6$; table 1). Restricting the analysis to women with only one child, the risk of cardiovascular death was much higher. Adjusted hazard ratios were 3.4 (2.6 to 4.6) after term pre-eclampsia and 9.4 (6.5 to 13.7) after preterm pre-eclampsia. These mortality hazard ratios fell to 1.5 and 2.4 , respectively, among the women with pre-eclampsia who went on to have more births. Their excess risk of non-cardiovascular death disappeared entirely.

\section{Cumulative mortality curves}

Figure $1 \Downarrow$ shows cumulative rates of death by year, from the year of first pregnancy. We compared maternal death by the outcome of the first pregnancy (term birth and no pre-eclampsia, term pre-eclampsia, and preterm pre-eclampsia). In separate panels, we presented risks for women with only one child and those with two or more. The cumulative rate of cardiovascular mortality among women with preterm pre-eclampsia was $9.2 \%$ after having only one child, falling to $1.1 \%$ for those women with two or more children (adjusted hazard ratio 5.0, 95\% confidence interval 2.4 to 10 ). With term pre-eclampsia, the rates were $2.8 \%$ and $1.1 \%$, respectively.

\section{Subcategories of cardiovascular mortality}

We divided cardiovascular mortality into its two main subgroups (ischaemic heart disease and stroke) to determine whether the associations with parity and pre-eclampsia differed between these two types of deaths. The patterns for these two groups were similar to each other (table 2). For comparison, we also presented results for other circulatory causes-these hazard ratios were lower than for ischaemic heart disease and stroke, especially for women with preterm pre-eclampsia and only one lifetime pregnancy.

\section{Interaction of pre-eclampsia and one child mothers in predicting mortality}

Data in table 1 and figure 1 suggested that having only one child strongly interacts with preterm pre-eclampsia in predicting subsequent cardiovascular and total mortality. We tested this interaction using a Wald test $(\mathrm{df}=1)$, which showed a significant association $\left(\chi^{2}=8.3, P=0.004\right.$ (cardiovascular mortality); $\chi^{2}=15.1$, $\mathrm{P}<0.001$ (all cause mortality)). This result remained significant in the adjusted model $\left(\chi^{2}=4.9, \mathrm{P}=0.028 ; \chi^{2}=7.3, \mathrm{P}=0.007\right.$, respectively). We saw little evidence for an interaction of having one child with term pre-eclampsia in predicting subsequent cardiovascular and total mortality $(\mathrm{P}>0.1)$.

\section{Maternal age at first birth and cardiovascular mortality}

We explored the effects of maternal age at the time of first pregnancy in the observed associations. Preterm pre-eclampsia was much more strongly associated with cardiovascular mortality for women who had their only child before age 30 years than after 30 years (adjusted hazard ratio 14.0 (95\% confidence interval 8.7 to 23 ) v 4.4 (2.4 to 8 )). Both estimates were relative to women in the same age category with two or more lifetime births and a term first pregnancy without pre-eclampsia.

\section{Maternal age and cardiovascular mortality}

We assessed the age specific risk of cardiovascular death associated with parity and pre-eclampsia (fig $2 \Downarrow$ ). Women with only one pregnancy consistently had higher relative risk of cardiovascular mortality at younger ages than at older ages. This association was true regardless of whether the first pregnancy was pre-eclamptic or not, although the risk of death was obviously higher in the presence of pre-eclampsia than in its absence. By contrast, women who had two or more pregnancies had a lower risk of cardiovascular death overall; no evidence of an increased relative risk was seen at younger maternal ages.

\section{The role of diabetes or hypertension}

Previously existing illnesses such as diabetes or hypertension might contribute to the observed associations, since these conditions increase the risk for pre-eclampsia and also cardiovascular disease. To the extent that women with diabetes or hypertension are discouraged from having additional pregnancies, this would contribute to the interaction of parity with pre-eclampsia. We expected that diabetes and pre-existing hypertension were under-reported in the registry, but that the recorded diagnoses were generally correct. We explored the possible role of diabetes by excluding $4322(0.5 \%)$ women with recorded pre-gestational or gestational diabetes in their first pregnancy. After excluding these women, the adjusted hazard ratio of cardiovascular mortality with preterm pre-eclampsia fell from 9.4 (95\% confidence interval 6.5 to 13.7 ; table 1) to 6.8 (4.3 to 11). A corresponding exclusion of women with pre-existing hypertension had little effect on the hazard ratios.

\section{Pre-eclampsia and mortality among fathers}

Pre-eclampsia in the first pregnancy had no role in the mortality of fathers. For fathers with two or more children, term pre-eclampsia in the first pregnancy was associated with an all cause mortality ratio of 1.02 (95\% confidence interval 0.95 to 1.1 ), and preterm pre-eclampsia with a mortality ratio of 0.99 ( 0.82 to 1.2$)$. As with one child mothers, fathers with only one child had a higher risk of all cause mortality than those with two or more children (adjusted hazard ratio 1.6, 95\% confidence interval 1.5 to 1.6 ), but this risk was unaffected by their partner's pre-eclampsia (1.5 (1.4 to 1.7) for term pre-eclampsia, 1.6 (1.3 to 1.9$)$ for preterm pre-eclampsia). The results were similar for cardiovascular and other causes of death.

\section{Social factors}

Women's education (stratified into three levels) was strongly associated with cardiovascular death (low $v$ high level of education; adjusted hazard ratio 3.0, 95\% confidence interval 2.6 to 3.5). In most analyses, we adjusted for maternal education. Further analyses stratified by education suggested possible interactions with education. Among women who had reached a low level of education, those with preterm pre-eclampsia and one child had an increased risk of cardiovascular death (7.9 (5.1 to 12)). Those women who had reached a high level of education had a larger increase in risk if they had a pre-eclamptic first pregnancy and only one lifetime child (21 (9.2 to 49)).

Women who were unmarried at first birth were more likely to have only one child than women married at their first birth. After excluding unmarried women from the main analysis 
(cardiovascular deaths section in table 1), the adjusted hazard ratio for women with preterm pre-eclampsia and one lifetime birth increased slightly (from 9.4 to 10.9 ).

\section{Pre-eclampsia in later pregnancies}

Some authors have reported an increased risk of mortality after repeated pre-eclampsia. ${ }^{12}{ }^{13} \mathrm{We}$ therefore considered the possible consequences of having more than one affected pregnancy. Table $3 \Downarrow$ shows associations of recurrent pre-eclampsia with later cardiovascular mortality. We saw a weak increase in risk of cardiovascular death among women with two or more lifetime births and pre-eclampsia in the first pregnancy (adjusted hazard ratio $1.5,95 \%$ confidence interval 1.2 to 1.9 ). The risk was slightly higher for women with pre-eclampsia in a later pregnancy regardless of whether the condition had also occurred in the first pregnancy $(2.0,1.2$ to 3.3$)$ or not $(2.0,1.5$ to 2.6$)$. Women with preterm pre-eclampsia in a later birth had a higher risk of cardiovascular death (3.0, 1.9 to 4.9). We did not have power in the data to fully explore the effects of recurrent preterm pre-eclampsia.

\section{Discussion}

Women with a history of pre-eclampsia have consistently been found to have a strongly increased risk of cardiovascular disease and death-particularly women with preterm or severe pre-eclampsia. ${ }^{2-5}$ 12-15 This association is considered sufficient by the American Heart Association to justify obstetric referral of affected women for cardiovascular follow-up. ${ }^{16}$

Recent studies by Grundy and Kravdal ${ }^{67}$ suggested that parity is a factor in maternal mortality that has not yet been explored. Specifically, the authors showed that women with one pregnancy were at higher risk of mortality in general, and from cardiovascular disease specifically. This association raises new questions regarding previous observations with pre-eclampsia, which have considered pre-eclampsia in the first pregnancy without regard to number of subsequent pregnancies.

Using data from the Norwegian birth and mortality registries, we found that the well known association of pre-eclampsia in the first pregnancy and lifetime cardiovascular mortality is strongly affected by whether women have a subsequent pregnancy. This is most apparent for women who have preterm pre-eclampsia in their first pregnancy. Those who have no more children have a ninefold increased risk, whereas those who go on to have more pregnancies have a 2.4 -fold risk. This high risk to women with preterm pre-eclampsia and only one child has not been previously reported. Studies have focused on the high risk for women with many pregnancies, ${ }^{17}{ }^{18}$ and a small study even concluded that nulliparous women have the lowest risk for cardiovascular disease. ${ }^{19}$

\section{Possible underlying mechanisms}

The association of pre-eclampsia with subsequent cardiovascular mortality has been discussed as perhaps resulting from the changes that occur during pre-eclampsia. Severe endothelial dysfunction can occur with pre-eclampsia, and these endothelial changes might in turn increase the risk of cardiovascular disease. ${ }^{20-22}$ It seems unlikely, however, that an additional pregnancy could physiologically reverse such changes. Several non-causal mechanisms might explain this association.

\section{Truncation by mortality}

The association could be an artefact of early deaths among women with one pregnancy who are thus unable to have additional pregnancies. We looked at this factor in several ways, with perhaps the most convincing observation being the relatively late increase in cardiovascular risk after first pregnancy (fig 1). Virtually no excess mortality was observed within the first 10 years after the first pregnancy, during which time most women would have had the opportunity to have a second birth if they wanted one (95\% of women in our cohort had their second birth within seven years of the first). Excluding all women who died within the first years after the first birth did not change our hazard ratio estimates.

\section{Voluntary limitation of family size}

Another possible explanation for the association is that women with severe underlying disease may be advised against further pregnancies by their physician. In support of this, we found that women with preterm pre-eclampsia and diabetes were less likely to continue to a second pregnancy than those without either condition (relative risk $0.60,95 \%$ confidence interval 0.47 to 0.75). Although we could not determine the extent to which health considerations might influence a woman's decision to have more children, adjusting for pre-existing diabetes reduced the strength of the association. Since diabetes in pregnancy is under-diagnosed and under-reported, the association could be reduced even further with more complete data for diabetes and other risk factors.

\section{Involuntary infertility}

Reduced fertility after pre-eclampsia in a first pregnancy may not be intentional. Underlying conditions predisposing to pre-eclampsia and cardiovascular mortality might themselves decrease the ability to have more children. Diabetes and obesity are specific factors that increase a woman's risk of pre-eclampsia, ${ }^{23-27}$ her risk of cardiovascular disease, ${ }^{28}{ }^{29}$ and infertility. ${ }^{30}{ }^{31}$ Diabetes and other risk factors would not necessarily have to be clinically recognised to have this effect. Subfertility has been associated with increased risk even after controlling for known cardiovascular disease risk factors. ${ }^{32}$ Pre-eclampsia may itself be an early expression of undiagnosed cardiovascular disease risk factors. ${ }^{33}$

\section{Social confounding}

Social class and education have been associated with cardiovascular risk factors and also with parity. Their role must therefore be considered in the associations described here. However, lower social class and education, which is usually accompanied by increased risk of cardiovascular disease, is usually also associated with less effective fertility control and more pregnancies. This would not create the observed associations. Our analysis of fathers provides further evidence that social factors are not the underlying cause. To the extent that such confounding was present, the associations would presumably be expressed in the cardiovascular risk of the fathers as well, since the two parents share social factors. In our data, father's cardiovascular death risk was not associated with pre-eclampsia in his partner, providing no support for socioeconomic confounding. The associations actually appeared stronger in well educated women and married women.

However, as with mothers, fathers with only one child have an increased risk of early death. The associations of male infertility with cardiovascular disease risk factors such as obesity ${ }^{34}$ and diabetes $^{35}$ may contribute to this association. 


\section{Comparisons with other studies}

There is an extensive literature on the association of pregnancy complications with cardiovascular diseases in mothers. ${ }^{36-39}$ Most studies have focused on first pregnancies, which is an approach that simplifies both the study design and analysis. Also, pre-eclampsia has often been regarded as primarily a disease of first pregnancies (even though risk is certainly not zero in subsequent pregnancies). Although pre-eclampsia data are usually available for later pregnancies, ${ }^{12}{ }^{13} 36$ investigators have given little attention to parity, and none has considered the association of pre-eclampsia and mortality in women with only one pregnancy.

We have used preterm pre-eclampsia as a surrogate measure of pre-eclampsia severity. Preterm delivery in the absence of pre-eclampsia has itself been shown to be an independent (if weaker) risk factor for cardiovascular death. ${ }^{36}{ }^{40}$ The extent to which undiagnosed pre-eclampsia might contribute to that association has not been explored.

Women with pre-eclampsia in two or more pregnancies have been suggested to be at particularly high risk for cardiovascular death. ${ }^{4-43}$ This effect was not confirmed in our data, except among the small number of women with two or more pre-eclamptic pregnancies after their first pregnancy. The fact that risk factors for pre-eclampsia and cardiovascular disease become stronger with age provides further support for the hypothesis of shared risk factors as the basis for the associations.

\section{Strengths and weaknesses}

Weaknesses of this study included a lack of detailed data on underlying cardiovascular risk factors before and after pregnancy, lack of information on important covariates such as body mass index and smoking, and an absence of any information on why women might have had only one child. Strengths of the study included its use of a large national cohort of women with complete prospective registration of exposures and outcomes, including total reproduction of all women in the cohort. Also, the data provided mortality follow-up for up to 42 years after the first birth, with a median follow-up of 25 years.

\section{Relevance for other populations and for prevention}

We expect that these results would apply to other populations with similar reproduction patterns. In Norway, about $85 \%$ of women who had one pregnancy went on to have a second. This proportion was fairly constant throughout the study period. In populations with a lower general fertility rate, stratification of women with one pregnancy might not show the same extreme heterogeneity in hazard ratios-which we believe is due to selective factors that isolate high risk women in the one child group.

As many other investigators have suggested, ${ }^{25} 3844-46$ pre-eclampsia can be a useful marker of a woman's cardiovascular risk. However, our data showed that not all women with pre-eclampsia are at high risk. Excess risk was particularly concentrated among women with preterm pre-eclampsia in their first pregnancy and no subsequent children. This group accounted for only $25 \%$ of all preterm pre-eclampsia cases at first pregnancy, but nearly two thirds of cardiovascular deaths. Rather than regard all women with pre-eclampsia as candidates for special monitoring (as current clinical guidelines recommend) ${ }^{16}$ consideration should be given to one child mothers-especially if their pre-eclampsia was preterm. By contrast, women who have term pre-eclampsia in their first pregnancy and go on to have unaffected pregnancies have only modest elevations in risk of cardiovascular disease.

We thank reviewers and colleagues for their advice and help on previous versions of this paper, in particular Jørn Olsen, Tine B Henriksen, Matt Gilman, Janet Rich-Edwards, and James Roberts.

Contributors: RS proposed the study, did the data analysis and the graphs, and drafted the manuscript. AJW, KK, LMI, BEV, LJV, and RTL reviewed the preliminary analyses and initial draft of the manuscript and provided critical comments. All the authors reviewed the final version of the manuscript. RS is the guarantor, has full access to all of the data in the study, and takes responsibility for the integrity of the data and the accuracy of the data analysis.

Funding: The study has been supported by grants from the Norwegian Research Council and by the Intramural Research Program of the National Institute of Environmental Health Sciences, National Institute of Health. The authors' institutions had no role in the design and conduct of the study; the collection, management, analysis, and interpretation of the data; or the preparation, review, or approval of the manuscript.

Competing interests: All authors have completed the Unified Competing Interest form at www.icmje.org/coi_disclosure.pdf (available on request from the corresponding author) and declare: support from the Norwegian Research Council and the National Institute of Environmental Health Sciences; no financial relationships with any organisations that might have an interest in the submitted work in the previous three years, no other relationships or activities that could appear to have influenced the submitted work.

Ethical approval: The study was approved by the internal review board of the Medical Birth Registry of Norway and by the regional ethics committee, REK Vest, Norway (2009/1868).

Data sharing: No additional data available.

Chesley LC. Remote prognosis after eclampsia. Perspect Nephrol Hypertens 1976;5:31-40. 2 Jonsdottir LS, Arngrimsson R, Geirsson RT, Sigvaldason H, Sigfusson N. Death rates from ischemic heart disease in women with a history of hypertension in pregnancy. Acta Obstet Gynecol Scand 1995;74:772-6.

3 Irgens HU, Reisaeter L, Irgens LM, Lie RT. Long term mortality of mothers and fathers after pre-eclampsia: population based cohort study. BMJ 2001;323:1213-7.

4 Funai EF, Friedlander Y, Paltiel O, Tiram E, Xue X, Deutsch L, et al. Long-term mortality after preeclampsia. Epidemiology 2005;16:206-15.

5 Smith GC, Pell JP, Walsh D. Pregnancy complications and maternal risk of ischaemic heart disease: a retrospective cohort study of 129,290 births. Lancet 2001;357:2002-6.

6 Grundy E, Kravdal O. Reproductive history and mortality in late middle age among Norwegian men and women. Am J Epidemiol 2008;167:271-9.

7 Grundy E, Kravdal O. Fertility history and cause-specific mortality: a register-based analysis of complete cohorts of Norwegian women and men. Soc Sci Med 2010;70:1847-57.

8 Irgens LM. The Medical Birth Registry of Norway. Epidemiological research and surveillance throughout 30 years [see comments]. Acta Obstet Gynecol Scand 2000;79:435-9.

9 National High Blood Pressure Education Program Working Group Report on High Blood Pressure in Pregnancy. Am J Obstet Gynecol 1990;163:1691-712.

10 Vestrheim LC, Melve KK, Roten LT, Tappert C, Araya E, Tollaksen K. Classification of pre-eclamptic pregnancies in health registries. Pregnancy Hypertension 2010;1 (S):S56-7.

11 Klungsoyr K, Morken NH, Irgens L, Vollset SE, Skjaerven R. Secular trends in the epidemiology of pre-eclampsia throughout 40 years in Norway: prevalence, risk factors and perinatal survival. Paediatr Perinat Epidemiol 2012;26:190-8.

12 Wikstrom AK, Haglund B, Olovsson M, Lindeberg SN. The risk of maternal ischaemic heart disease after gestational hypertensive disease. BJOG 2005;112:1486-91.

13 Lykke JA, Langhoff-Roos J, Sibai BM, Funai EF, Triche EW, Paidas MJ. Hypertensive pregnancy disorders and subsequent cardiovascular morbidity and type 2 diabetes mellitus in the mother. Hypertension 2009;53:944-51.

14 Wilson BJ, Watson MS, Prescott GJ, Sunderland S, Campbell DM, Hannaford P, et al. Hypertensive diseases of pregnancy and risk of hypertension and stroke in later life: results from cohort study. BMJ 2003;326:845.

15 Arnadottir GA, Geirsson RT, Arngrimsson R, Jonsdottir LS, Olafsson O. Cardiovascular death in women who had hypertension in pregnancy: a case-control study. BJOG 2005;112:286-92.

16 Mosca L, Benjamin EJ, Berra K, Bezanson JL, Dolor RJ, Lloyd-Jones DM, et al. Effectiveness-based guidelines for the prevention of cardiovascular disease in women-2011 update: a guideline from the american heart association. Circulation 2011;123:1243-62

17 Christensen K, Gaist D, Jeune B, Vaupel JW. A tooth per child? Lancet 1998;352:204.

18 Lawlor DA, Emberson JR, Ebrahim S, Whincup PH, Wannamethee SG, Walker M, et al. Is the association between parity and coronary heart disease due to biological effects of pregnancy or adverse lifestyle risk factors associated with child-rearing? Findings from the British Women's Heart and Health Study and the British Regional Heart Study. Circulation 2003;107:1260-4. 


\section{What is already known on this topic}

Women with a pre-eclamptic pregnancy are at increased risk of death from cardiovascular disease

This conclusion has been based largely on studies of outcome of first births

\section{What this study adds}

Excess risk of cardiovascular death was concentrated among women with preterm pre-eclampsia in their first pregnancy and no subsequent children

The association might be due to health problems that discourage or prevent further pregnancies

Women who have term pre-eclampsia in their first pregnancy and go on to have unaffected pregnancies have only modest elevations in risk

19 Catov JM, Newman AB, Sutton-Tyrrell K, Harris TB, Tylavsky F, Visser M, et al. Parity and cardiovascular disease risk among older women: how do pregnancy complications mediate the association? Ann Epidemiol 2008;18:873-9.

20 Roberts JM, Taylor RN, Musci TJ, Rodgers GM, Hubel CA, McLaughlin MK. Preeclampsia: an endothelial cell disorder. Am J Obstet Gynecol 1989;161:1200-4.

21 Karumanchi SA, Maynard SE, Stillman IE, Epstein FH, Sukhatme VP. Preeclampsia: a renal perspective. Kidney Int 2005;67:2101-13.

22 Mutter WP, Karumanchi SA. Molecular mechanisms of preeclampsia. Microvasc Res 2008;75:1-8.

23 Wolf M, Hubel CA, Lam C, Sampson M, Ecker JL, Ness RB, et al. Preeclampsia and future cardiovascular disease: potential role of altered angiogenesis and insulin resistance. $J$ Clin Endocrinol Metab 2004;89:6239-43.

24 Solomon CG, Seely EW. Brief review: hypertension in pregnancy: a manifestation of the insulin resistance syndrome? Hypertension 2001;37:232-9.

25 Rodie VA, Freeman DJ, Sattar N, Greer IA. Pre-eclampsia and cardiovascular disease: metabolic syndrome of pregnancy? Atherosclerosis 2004;175:189-202.

26 Chappell LC, Enye S, Seed P, Briley AL, Poston L, Shennan AH. Adverse perinata outcomes and risk factors for preeclampsia in women with chronic hypertension: a prospective study. Hypertension 2008;51:1002-9.

27 Romundstad PR, Magnussen EB, Smith GD, Vatten LJ. Hypertension in pregnancy and later cardiovascular risk: common antecedents? Circulation 2010;122:579-84.

28 Marks JB, Raskin P. Cardiovascular risk in diabetes: a brief review. J Diabetes Complications 2000;14:108-15.

29 Aronne LJ, Brown WV, Isoldi KK. Cardiovascular disease in obesity: a review of related risk factors and risk-reduction strategies. J Clin Lipidol 2007;1:575-82.

30 Jonasson JM, Brismar K, Sparen P, Lambe M, Nyren O, Ostenson CG, et al. Fertility in women with type 1 diabetes: a population-based cohort study in Sweden. Diabetes Care 2007;30:2271-6

31 Whitworth KW, Baird DD, Stene LC, Skjaerven R, Longnecker MP. Fecundability among women with type 1 and type 2 diabetes in the Norwegian Mother and Child Cohort Study. Diabetologia 2010;54:516-22.

32 Parikh NI, Cnattingius S, Mittleman MA, Ludvigsson JF, Ingelsson E. Subfertility and risk of later life maternal cardiovascular disease. Hum Reprod 2012;27:568-75.

33 Gordin D, Kaaja R, Forsblom C, Hiilesmaa V, Teramo K, Groop PH. Pre-eclampsia and pregnancy-induced hypertension are associated with severe diabetic retinopathy in type 1 diabetes later in life. Acta Diabetol 2012; published online 7 Sept, doi:10.1007/s00592012-0415-0.

34 Sallmen M, Sandler DP, Hoppin JA, Blair A, Baird DD. Reduced fertility among overweight and obese men. Epidemiology 2006:17:520-3.
35 Glenn DR, McClure N, Lewis SE. The hidden impact of diabetes on male sexual dysfunction and fertility. Hum Fertil (Camb) 2003;6:174-9.

36 Catov JM, Wu CS, Olsen J, Sutton-Tyrrell K, Li J, Nohr EA. Early or recurrent preterm birth and maternal cardiovascular disease risk. Ann Epidemiol 2010;20:604-9.

37 Oberg S, Cnattingius S, Sandin S, Lichtenstein P, Iliadou AN. Birth weight predicts risk of cardiovascular disease within dizygotic but not monozygotic twin pairs: a large population-based co-twin-control study. Circulation 2011:123:2792-8.

38 Bellamy L, Casas JP, Hingorani AD, Williams DJ. Pre-eclampsia and risk of cardiovascular disease and cancer in later life: systematic review and meta-analysis. BMJ 2007;335:974.

39 Smith GD, Hypponen E, Power C, Lawlor DA. Offspring birth weight and parental mortality prospective observational study and meta-analysis. Am J Epidemiol 2007;166:160-9.

40 Hastie CE, Smith GC, Mackay DF, Pell JP. Maternal risk of ischaemic heart disease following elective and spontaneous pre-term delivery: retrospective cohort study of 750 350 singleton pregnancies. Int J Epidemiol 2011:40:914-9.

41 Sibai BM, el-Nazer A, Gonzalez-Ruiz A. Severe preeclampsia-eclampsia in young primigravid women: subsequent pregnancy outcome and remote prognosis. Am J Obstet Gynecol 1986;155:1011-6.

42 Roberts JM. Pre-eclampsia and cardiovascular disease later in life. who is at risk? BMJ 2001;323:1217.

43 Chesley LC. Recognition of the long-term sequelae of eclampsia. Am J Obstet Gynecol 2000;182:249-50.

44 Sattar N, Greer IA. Pregnancy complications and maternal cardiovascular risk: opportunities for intervention and screening? BMJ 2002;325:157-60.

45 Rich-Edwards JW. Reproductive health as a sentinel of chronic disease in women Womens Health (Lond Engl) 2009:5:101-5.

46 Rich-Edwards JW, McElrath TF, Karumanchi SA, Seely EW. Breathing life into the lifecourse approach: pregnancy history and cardiovascular disease in women. Hypertension 2010;56:331-4.

Accepted: 02 November 2012

\section{Cite this as: BMJ 2012:345:e7677}

This is an open-access article distributed under the terms of the Creative Commons Attribution Non-commercial License, which permits use, distribution, and reproduction in any medium, provided the original work is properly cited, the use is non commercial and is otherwise in compliance with the license. See: http://creativecommons.org/licenses/bync/2.0/ and http://creativecommons.org/licenses/by-nc/2.0/legalcode. 


\section{Tables}

\begin{tabular}{|c|c|c|c|c|c|c|c|}
\hline \multirow[b]{2}{*}{$\begin{array}{l}\text { Outcome of first } \\
\text { pregnancy }\end{array}$} & \multirow[b]{2}{*}{$\begin{array}{l}\text { No of } \\
\text { women }\end{array}$} & \multicolumn{2}{|c|}{ All deaths } & \multicolumn{2}{|c|}{ Cardiovascular deaths } & \multicolumn{2}{|c|}{ Non-cardiovascular deaths $\dagger$} \\
\hline & & $\begin{array}{l}\text { No of deaths } \\
\text { (per 1000) }\end{array}$ & $\begin{array}{c}\text { Adjusted hazard } \\
\text { ratio }(95 \% \mathrm{Cl}) \neq\end{array}$ & $\begin{array}{l}\text { No of deaths } \\
\text { (per 1000) }\end{array}$ & $\begin{array}{l}\text { Adjusted hazard } \\
\text { ratio }(95 \% \mathrm{Cl}) \neq\end{array}$ & $\begin{array}{l}\text { No of deaths } \\
\text { (per 1000) }\end{array}$ & $\begin{array}{c}\text { Adjusted hazard } \\
\text { ratio }(95 \% \mathrm{Cl}) \ddagger\end{array}$ \\
\hline \multicolumn{8}{|l|}{ All women } \\
\hline No pre-eclampsia & 801323 & $22107(27.6)$ & 1.0 (reference) & $2380(3.0)$ & 1.0 (reference) & $18456(23.0)$ & 1.0 (reference) \\
\hline All pre-eclampsia & 34824 & $902(25.9)$ & $1.1(1.0$ to 1.1$)$ & $176(5.1)$ & $1.9(1.6$ to 2.2$)$ & $660(19.0)$ & $0.93(0.86$ to 1.00$)$ \\
\hline $\begin{array}{l}\text { No pre-eclampsia, } \\
\text { term birth }\end{array}$ & 712181 & $19214(27.0)$ & 1.0 (reference) & $2011(2.8)$ & 1.0 (reference) & $16129(22.6)$ & 1.0 (reference) \\
\hline Term pre-eclampsia & 26708 & $674(25.2)$ & $1.0(0.94$ to 1.1$)$ & $115(4.3)$ & $1.6(1.4$ to 2.0$)$ & $512(19.2)$ & $0.92(0.85$ to 1.01$)$ \\
\hline $\begin{array}{l}\text { Preterm } \\
\text { pre-eclampsia }\end{array}$ & 5886 & $169(28.7)$ & $1.4(1.2$ to 1.6$)$ & $45(7.6)$ & $3.7(2.7$ to 4.8$)$ & $111(18.9)$ & 1.08 (0.89 to 1.31$)$ \\
\hline \multicolumn{8}{|c|}{ Women with one lifetime pregnancy } \\
\hline $\begin{array}{l}\text { No pre-eclampsia, } \\
\text { term birth }\end{array}$ & 112208 & $5311(47.3)$ & $1.9(1.8$ to 1.9$)$ & $596(5.3)$ & $2.0(1.8$ to 2.2$)$ & $4382(39.1)$ & $1.8(1.8$ to 1.9$)$ \\
\hline Term pre-eclampsia & 4758 & $227(47.7)$ & $1.8(1.6$ to 2.1$)$ & $47(9.9)$ & $3.4(2.6$ to 4.6$)$ & $163(34.3)$ & $1.6(1.4$ to 1.9$)$ \\
\hline $\begin{array}{l}\text { Preterm } \\
\text { pre-eclampsia }\end{array}$ & 1426 & $92(64.5)$ & $3.1(2.5$ to 3.9$)$ & $29(20.3)$ & $9.4(6.5$ to 13.7$)$ & $57(40.0)$ & $2.3(1.7$ to 3.0$)$ \\
\hline \multicolumn{8}{|c|}{ Women with two or more lifetime pregnancies } \\
\hline $\begin{array}{l}\text { No pre-eclampsia, } \\
\text { term birth }\end{array}$ & 599973 & $13903(23.2)$ & 1.0 (reference) & $1415(2.4)$ & 1.0 (reference) & $11746(19.6)$ & 1.0 (reference) \\
\hline Term pre-eclampsia & 21950 & $447(20.4)$ & $1.0(0.90$ to 1.1$)$ & $68(3.1)$ & $1.5(1.2$ to 2.0$)$ & $349(15.9)$ & 0.93 (0.84 to 1.04$)$ \\
\hline $\begin{array}{l}\text { Preterm } \\
\text { pre-eclampsia }\end{array}$ & 4460 & $77(17.3)$ & $1.1(0.87$ to 1.4$)$ & $16(3.6)$ & $2.4(1.5$ to 3.9$)$ & $54(12.1)$ & 0.89 (0.68 to 1.2$)$ \\
\hline
\end{tabular}

*Ischaemic heart disease and stroke combined, excluding other circulatory conditions (see table 2).

†Excluding all circulatory conditions.

$\ddagger$ Adjusted for maternal education (three categories), maternal age at first birth, and year of first birth. 
Table 2| Long term mortality from circulatory causes in women with pre-eclampsia during first singleton pregnancy

\begin{tabular}{|c|c|c|c|c|c|c|c|}
\hline \multirow[b]{2}{*}{$\begin{array}{l}\text { Outcome of first } \\
\text { pregnancy }\end{array}$} & \multirow[b]{2}{*}{$\begin{array}{c}\text { No of } \\
\text { women }\end{array}$} & \multicolumn{2}{|c|}{$\begin{array}{l}\text { Ischaemic heart disease (codes } \\
\qquad 120-125)^{\star}\end{array}$} & \multicolumn{2}{|c|}{$\begin{array}{l}\text { Cerebrovascular disease (stroke, } \\
\text { codes } 160-169)^{\star}\end{array}$} & \multicolumn{2}{|c|}{ All other circulatory causes } \\
\hline & & $\begin{array}{l}\text { No of deaths } \\
\text { (per 1000) }\end{array}$ & $\begin{array}{l}\text { Adjusted hazard } \\
\text { ratio }(95 \% \mathrm{Cl}) \dagger\end{array}$ & $\begin{array}{l}\text { No of deaths } \\
\text { (per 1000) }\end{array}$ & $\begin{array}{l}\text { Adjusted hazard } \\
\text { ratio }(95 \% \mathrm{Cl}) \dagger\end{array}$ & $\begin{array}{l}\text { No of deaths } \\
\text { (per 1000) }\end{array}$ & $\begin{array}{l}\text { Adjusted hazard } \\
\text { ratio }(95 \% \mathrm{Cl}) \dagger\end{array}$ \\
\hline \multicolumn{8}{|c|}{ Women with one lifetime pregnancy } \\
\hline $\begin{array}{l}\text { No pre-eclampsia, } \\
\text { term birth }\end{array}$ & 112208 & $313(2.8)$ & $2.0(1.8$ to 2.4$)$ & $294(2.6)$ & 1.9 (1.6 to 2.2$)$ & $332(3.0)$ & $2.0(1.8$ to 2.4$)$ \\
\hline $\begin{array}{l}\text { Term } \\
\text { pre-eclampsia }\end{array}$ & 4758 & $34(7.1)$ & 4.7 (3.3 to 6.7$)$ & $14(2.9)$ & $2.1(1.2$ to 3.6$)$ & $17(3.6)$ & $2.4(1.5$ to 3.9$)$ \\
\hline $\begin{array}{l}\text { Preterm } \\
\text { pre-eclampsia }\end{array}$ & 1426 & $15(10.5)$ & $9.3(5.5$ to 15.6$)$ & $16(11.2)$ & $10.4(6.3$ to 17.2$)$ & $6(4.2)$ & $3.6(1.6$ to 8.0$)$ \\
\hline \multicolumn{8}{|c|}{ Women with two or more lifetime pregnancies } \\
\hline $\begin{array}{l}\text { No pre-eclampsia, } \\
\text { term birth }\end{array}$ & 599973 & $675(1.1)$ & 1.0 (reference) & $759(1.3)$ & 1.0 (reference) & $742(1.2)$ & 1.0 (reference) \\
\hline $\begin{array}{l}\text { Term } \\
\text { pre-eclampsia }\end{array}$ & 21950 & $37(1.7)$ & $1.7(1.2$ to 2.4$)$ & $32(1.5)$ & $1.4(0.95$ to 1.91$)$ & $30(1.3)$ & $1.3(0.89$ to 1.8$)$ \\
\hline $\begin{array}{l}\text { Preterm } \\
\text { pre-eclampsia }\end{array}$ & 4460 & $12(2.7)$ & 3.7 (2.1 to 6.6$)$ & $4(0.90)$ & $1.12(0.42$ to 3.0$)$ & $7(1.6)$ & $1.9(0.91$ to 4.0$)$ \\
\hline
\end{tabular}

*ICD-10 codes. ICD-10 covered the years 1996-2009, ICD-8 and ICD-9 covered years 1967-95 (see Methods).

†Adjusted for maternal education (three categories), maternal age at first birth, and year of first birth. 
Table 3| Long term cardiovascular death in women with recurrent pre-eclampsia in second, third, or fourth pregnancies

No of recurrences of pre-eclampsia in

Pre-eclampsia in first pregnancy second, third, or fourth pregnancies

No of women Maternal deaths (per 1000) Adjusted hazard ratio (95\% Cl)*

\begin{tabular}{|c|c|c|c|c|}
\hline No & 0 & 643559 & $1555(2.4)$ & 1.0 (reference) \\
\hline Yes & 0 & 22279 & $68(3.1)$ & $1.5(1.2$ to 1.9$)$ \\
\hline No & 1 & 13792 & $61(4.4)$ & 2.0 (1.5 to 2.6$)$ \\
\hline Yes & 1 & 4718 & $16(3.4)$ & 2.0 (1.2 to 3.3$)$ \\
\hline No & $\geq 2$ & 719 & $5(6.9)$ & $3.8(1.6$ to 9.1$)$ \\
\hline Yes & $\geq 2$ & 548 & $4(7.3)$ & 5.0 (1.9 to 13.3$)$ \\
\hline No & $\geq 1$ & 14511 & $66(4.5)$ & 2.1 (1.6 to 2.7 ) \\
\hline Yes & $\geq 1$ & 5266 & $20(3.8)$ & 2.3 (1.5 to 3.6$)$ \\
\hline No and yes combined & $\geq 1$ & 19777 & $86(4.3)$ & 2.1 (1.8 to 2.6$)$ \\
\hline
\end{tabular}

*Adjusted for maternal education (three categories), maternal age at first birth, and year of first birth. 


\section{Figures}

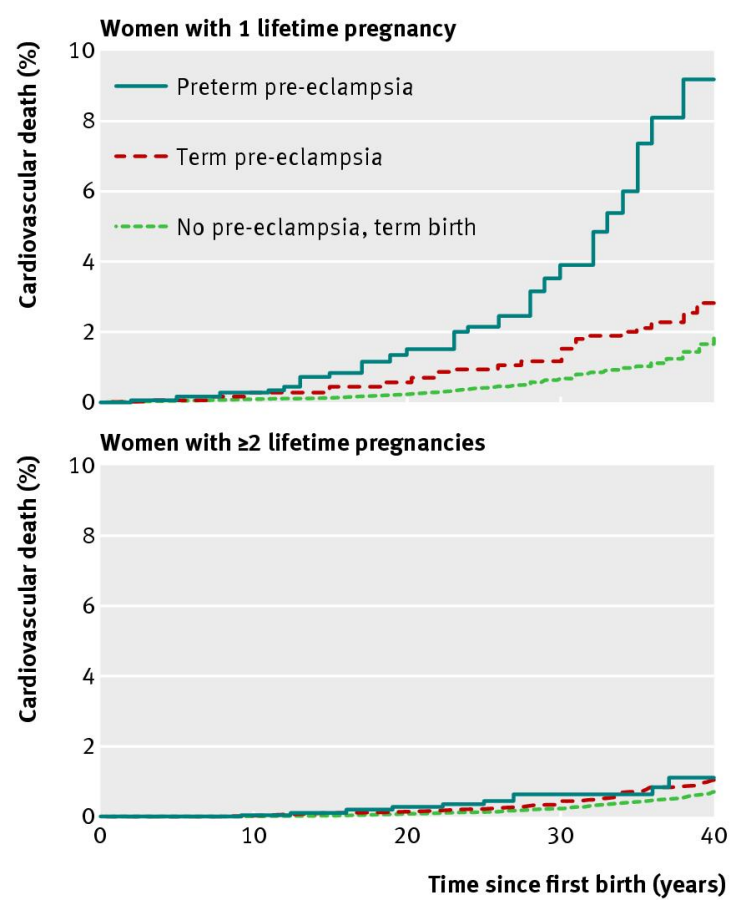

Fig 1 Cumulative risk of cardiovascular death for women according to pre-eclampsia status at first pregnancy and number of subsequent lifetime pregnancies
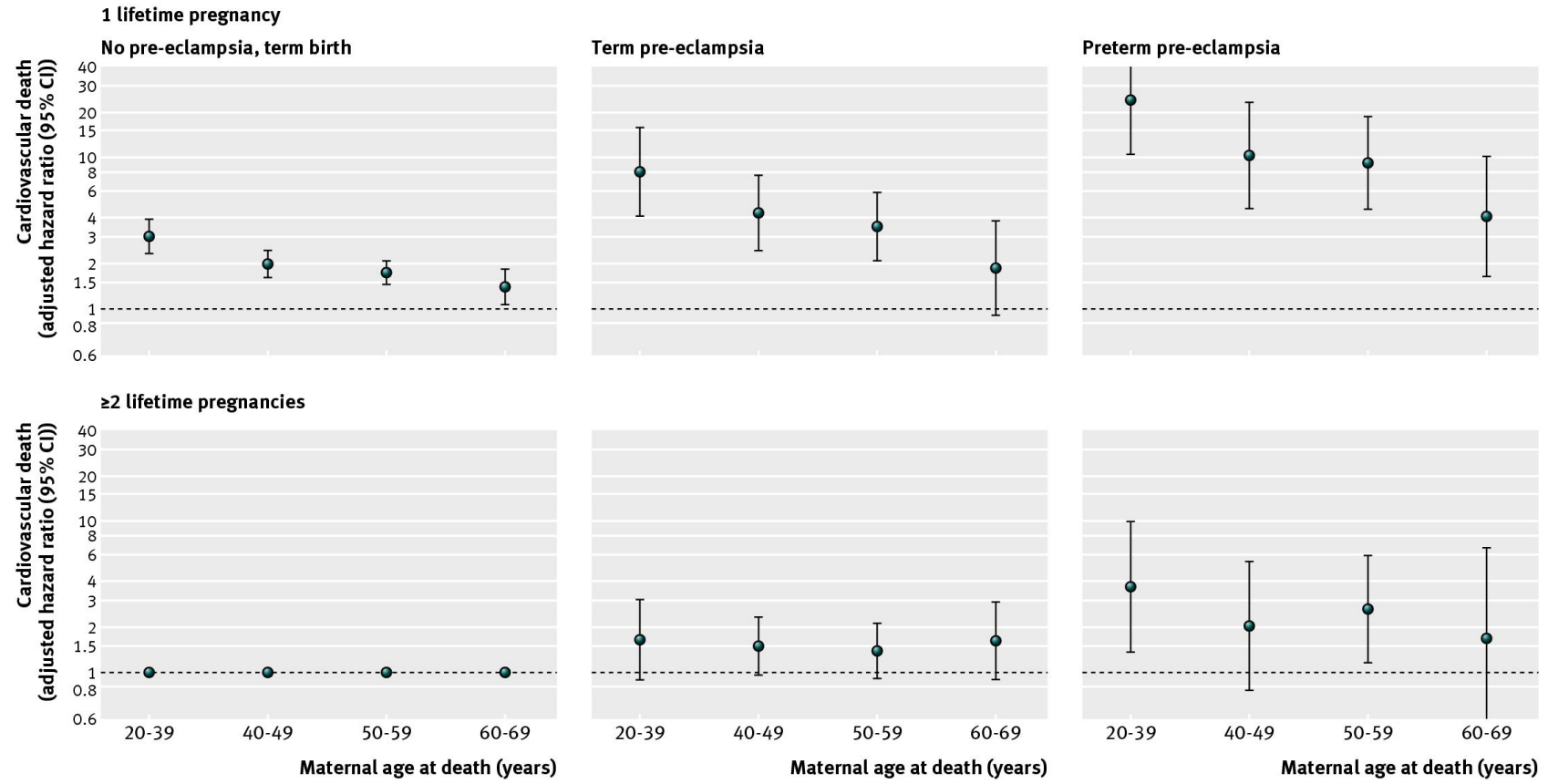

Fig 2 Age specific risk of cardiovascular death in mothers, according to parity and pre-eclampsia. Hazard ratios were adjusted for maternal age, year of first birth, and maternal education (three categories). References within each age group were women with a first birth born to term with no pre-eclampsia, and two or more lifetime births 